\title{
AMMI Canada position paper: 2012 Mandatory influenza immunization of health care workers
}

\author{
Elizabeth Bryce MD FRCPC ${ }^{1}$, Joanne Embree MD FRCPC ${ }^{2}$, Gerald Evans MD FRCPC ${ }^{3}$, Lynn Johnston MD FRCPC ${ }^{4}$, \\ Kevin Katz MD FRCPC ${ }^{5,6}$, Allison McGeer MD FRCPC ${ }^{6,7}$, Dorothy Moore MD FRCPC ${ }^{8}$, Virginia Roth MD FRCPC ${ }^{9}$, \\ Andrew Simor MD FRCPC 6,10,11, Kathryn Suh MD FRCPC ${ }^{9}$, Mary Vearncombe MD FRCPC 6,10,11
}

\begin{abstract}
STATEMENT
Annual influenza immunization should be required as a condition of new and ongoing employment or appointment for all workers who spend time in areas where patient care is provided and/or patients are present. ${ }^{1}$

\section{BURDEN OF INFLUENZA}

Influenza remains the most common infectious disease cause of death in Canada and is a frequent cause of outbreaks in both acute and long-term care facilities $(1,2)$. The majority of morbidity and mortality associated with influenza accrues to older adults, infants and individuals with significant underlying illnesses. While immunization is of significant benefit in these populations, vaccine efficacy is limited, and considerable morbidity and mortality occurs even in vaccinated persons $(3,4)$. Outbreaks of influenza in long-term care homes for the elderly are common, occurring in as many as $50 \%$ of institutions annually (5). In acute care, hospital-acquired influenza occurs at an estimated rate of three to eight per 1000 patient admissions and has a case fatality rate estimated to be $7 \%$ to $16 \%$ (6). For this reason, Canadian public health officials have, for nearly 30 years, recommended immunization not only of these at-risk populations, but also of close contacts and caregivers who may transmit influenza to them (3).
\end{abstract}

\section{BENEFITS OF HEALTH CARE WORKER INFLUENZA IMMUNIZATION}

In healthy adults 18 to 64 years of age, influenza immunization is approximately $60 \%$ effective in preventing infection overall, and reduces the duration and severity of symptoms in persons in whom infection occurs (7). Serious adverse events are rare and the benefits of influenza immunization of adults substantially outweigh the risks $(3,4)$.

As many as $26 \%$ of unvaccinated health care workers are infected with influenza annually, and transmission of influenza from health care workers to patients has been described in many different health care settings $(3-6,8,9)$. Influenza may be transmitted to patients by workers with symptomatic or asymptomatic infection, or before the onset of symptoms (10); many studies have documented that the majority of health care workers continue to work when ill with acute respiratory illness, including influenza (11-13).

Four randomized controlled trials have demonstrated that health care worker immunization in chronic care hospitals/long-term care homes for the elderly reduces patient mortality (14-17). The striking benefit - a $20 \%$ to $40 \%$ reduction in mortality during the influenza season - is consistent across studies, occurs only during periods of influenza activity and increases with increasing health care worker immunization rates. Observational studies also suggest that the risk of influenza outbreaks decreases as the immunization rate of health care workers increases $(5,18)$.

There are no randomized controlled trial data to assess the impact of health care worker vaccination on patient illness in acute or ambulatory care settings. However, the biological rationale for health care worker immunization does not vary from one health care setting to another. In acute care, two observational studies have found that lower health care worker immunization rates were associated with higher rates of laboratory-confirmed hospital-acquired influenza $(18,19)$, and transmission of influenza-like illness among and between health care workers and patients in acute care hospitals was common (20). The frequency and importance of this transmission is confirmed in influenza outbreaks in acute care, where health care worker attack rates mirror - and sometimes exceed - patient attack rates $(6,8,20,21)$. There are also mounting data confirming that protection is provided to close contacts of vaccinated individuals, strengthening the evidence from acute and long-term care that vaccination of health care workers not only reduces the risk of individual worker to patient transmission, but also reduces the overall risk of influenza in vulnerable patient populations $(22,23)$.

Modelling studies and observational data suggest that increases in health care worker immunization from any baseline will lead to incremental reduction in transmission and better patient protection; that is, optimal patient protection requires that all health care workers be vaccinated $(5,24,25)$.

\footnotetext{
${ }^{1}$ Infection Prevention and Control, Vancouver Coastal Health, Vancouver, British Columbia; ${ }^{2}$ Department of Medical Microbiology and Department of Pediatrics and Child Health, University of Manitoba, Winnipeg, Manitoba, ${ }^{3}$ Infection Prevention Eु Control Kingston General Hospital/Hotel Dieu Hospital, and Departments of Medicine, Biomedical Eु Molecular Sciences and Pathology Eु Molecular Medicine, Queen's University, Kingston, Ontario; ${ }^{4}$ Capital District Health Authority and Dalhousie University, Halifax, Nova Scotia; ${ }^{5}$ Infection Prevention and Control Program, North York General Hospital; ${ }^{6}$ Department of Laboratory Medicine and Pathobiology, University of Toronto; ${ }^{7}$ Infection Control, Mount Sinai Hospital, Toronto, Ontario; ${ }^{8}$ Montreal Children's Hospital, McGill University Health Centre, Montreal, Quebec;

${ }^{9}$ Infection Prevention and Control Program, Division of Infectious Diseases, The Ottawa Hospital, and the Department of Medicine, University of Ottawa, Ottawa, Ontario; ${ }^{10}$ Department of Microbiology, Sunnybrook Health Sciences Centre; ${ }^{11}$ Infection Prevention and Control, Sunnybrook Health Sciences Centre, Toronto, Ontario

Correspondence: Dr Allison McGeer, Room 210, Mount Sinai Hospital, 600 University Avenue, Toronto, Ontario, M5G 1 X5.

Telephone 416-586-3118, fax 416-586-8358, e-mail amcgeer@mtsinai.on.ca
} 


\section{VOLUNTARY HEALTH CARE WORKER INFLUENZA IMMUNIZATION PROGRAMS HAVE FAILED}

Despite this evidence, and despite efforts to promote health care worker immunization, influenza immunization rates among health care workers remain unacceptably low. For instance, the median rate of health care worker immunization in Toronto, Ontario, in 2010/2011 was $37 \%$ in acute care facilities and $58 \%$ in long-term care homes (26). In Ontario, immunization rates among health care workers in long-term care homes have been decreasing rather than increasing over the past five years (unpublished data, Ontario Ministry of Health and Long-Term Care).

Studies of health care worker immunization have demonstrated that single interventions (eg, provision of information, incentives) have either no effect, or an effect too small to be detected when studied (27). Programs that introduce multiple interventions simultaneously, which are based on principles of social marketing or quality improvement, and have strong and visible institutional support, have been reported to increase immunization rates by $10 \%$ to $25 \%(28-30)$. However, numerous studies of voluntary immunization programs have demonstrated that several years of multidisciplinary programs that have strong senior management support and include all of the nine components recommended by the United States Advisory Committee on Immunization Practices result in health care worker immunization rates of no greater than $65 \%$ to $75 \%$ (28-35). In addition, wavering of attention to such programs has rapidly resulted in decreases in immunization rates (35).

\section{MANDATORY HEALTH CARE WORKER INFLUENZA IMMUNIZATION PROGRAMS HAVE SUCCEEDED}

These data have resulted in public health departments and health care agencies considering various forms of requirement for health care worker immunization. Several American states now have laws that require hospital-based health care workers to either receive or formally decline influenza immunization each year (36), and an increasing number of health care agencies have implemented institutional requirements for annual influenza immunization among their employees and other staff. Reports from programs with requirements for immunization and termination of employees who refuse have

\section{REFERENCES}

1. Parkins MD, McNeil SA, Laupland KB. Routine immunization of adults in Canada: Review of the epidemiology of vaccinepreventable diseases and current recommendations for primary prevention. Can J Infect Dis Med Microbiol 2009;20:e81-90.

2. Kwong JC, Crowcroft NS, Campitelli MA, et al. Ontario Burden of Infectious Diseases Study. Ontario Agency for Health Protection and Promotion and the Institute for Clinical and Evaluative Sciences, Ontario, Canada. <www.ices.on.ca/file/ONBOIDS_ FullReport_intra.pdf $>$ (Accessed January 21, 2012).

3. National Advisory Committee on Immunization. Statement on Seasonal Influenza Vaccine for 2011-2012. CCDR 2011;37:ACS-5. $<$ www.phac-aspc.gc.ca/publicat/ccdr-rmtc/11vol37/acs-dcc-5/indexeng.php> (Accessed January 21, 2012).

4. Prevention and Control of Influenza with Vaccines: Recommendations of the Advisory Committee on Immunization Practices (ACIP), 2011. MMWR 2011;60(33);1128-32. <www.cdc.gov/mmwr/preview/mmwrhtml/mm6033a3.htm> (Accessed January 21, 2012).

5. Stevenson CG, McArthur MA, Naus M, Abraham E, McGeer AJ. Prevention of influenza and pneumococcal pneumonia in Canadian long-term care facilities: How are we doing? CMAJ 2001;164:1413-9.

6. Salgado CD, Farr BM, Hall KK, Hayden FG. Influenza in the acute hospital setting. Lancet Infect Dis 2002;2:145-55.

7. Osterholm MT, Kelley NS, Sommer A, Belongia EA. Efficacy and effectiveness of influenza vaccines: A systematic review and metaanalysis. Lancet Infect Dis 2012;12:36-44.

8. Cunney R, Bialachowski A, Thornley D, Smaill F, Pennie R. An outbreak of influenza $A$ in a neonatal intensive care unit. Infect Control Hosp Epidemiol 2000;21:449-54. demonstrated that such programs achieve immunization rates of $>90 \%$ sustained over time, result in termination of $<0.2 \%$ of employees, and are accepted and viewed positively by employees and other staff $(32,33,37,38)$.

\section{IMMUNIZATION AS A CONDITION OF EMPLOYMENT IS ETHICALLY JUSTIFIED}

As workers in occupations that are freely chosen, all persons who work in health care, but physicians in particular, are granted special privileges and powers by society. As a result, we also have specific obligations to do no harm, and to take all reasonable action to protect the patients we care for. Being vaccinated against influenza is a duty of care; the needs and safety of patients must come before the personal preferences of individual health care workers $(39,40)$.

Three criteria have been proposed that must be met to justify mandating compliance with a preventive intervention (41). First, there should be clear medical value from the intervention to the individual. Second, the public health benefit of the intervention must be clear. Third, a requirement must be considered the only option.

It is the position of AMMI Canada that these three criteria have been met in relation to health care workers and influenza immunization. Health care workers and their employers have an ethical obligation to act in the best interest of the patients for whom they provide care. Influenza immunization should be required annually for all workers who spend time in areas where patient care is provided and/or patients are present.

${ }^{1}$ Workers are defined as employees, physicians, contract workers, students and other consultants whose occupations require them to be present in areas where patient care is provided. When influenza is circulating in the local community, health care workers who cannot receive influenza vaccine because of a medical contraindication should be accommodated by reassignment or other methods used to protect patients [eg, health care worker wearing mask in patient care areas

9. Kuster SP, Shah PS, Coleman BL, et al. Incidence of influenza in healthy adults and healthcare workers: A systematic review and meta-analysis. PLoS One 2011;6:e26239.

10. Lau LL, Cowling BJ, Fang VJ, et al. Viral shedding and clinical illness in naturally acquired influenza virus infections. J Infect Dis 2010;201:1509-16.

11. Lester RT, McGeer A, Tomlinson G, Detsky AS. Use of, effectiveness of, and attitudes regarding influenza vaccine among house staff. Infect Control Hosp Epidemiol 2003;24:839-44.

12. Turnberg W, Daniell W, Duchin J. Influenza vaccination and sick leave practices and perceptions reported by health care workers in ambulatory care settings. Am J Infect Control 2010;38:486-8.

13. Coleman BL, Boggild AK, Drews SJ, Li Y, Low DE, McGeer AJ. Respiratory illnesses in Canadian health care workers: A pilot study of influenza vaccine and oseltamivir prophylaxis during the 2007/2008 influenza season. Influenza Other Resp Viruses 2011;5:404-8.

14. Carman WF, Elder AG, Wallace LA, et al. Effects of influenza vaccination of health-care workers on mortality of elderly people in long-term care: A randomised controlled trial. Lancet 2000;355:93-7.

15. Hayward AC, Harling R, Wetten S, et al. Effectiveness of an influenza vaccine programme for care home staff to prevent death, morbidity, and health service use among residents: Cluster randomised controlled trial. BMJ 2006;333:1241.

16. Lemaitre M, Meret T, Rothan-Tondeur M, et al. Effect of influenza vaccination of nursing home staff on mortality of residents: A cluster-randomized trial. J Am Geriatr Soc 2009;57:1580-6.

17. Potter J, Stott DJ, Roberts MA, et al. Influenza vaccination of health care workers in long-term-care hospitals reduces the mortality of elderly patients. J Infect Dis 1997;175:1-6. 
18. Benet $\mathrm{T}$, Regis $\mathrm{C}$, Voirin $\mathrm{N}$, et al. Influenza vaccination of healthcare workers in acute-care hospitals: A case-control study of its effect on hospital-acquired influenza among patients. BMC Infect Dis 2012;12:30.

19. Salgado CD, Giannetta ET, Hayden FG, Farr BM. Preventing nosocomial influenza by improving the vaccine acceptance rate of clinicians. Infect Control Hosp Epidemiol 2004;25:923-8.

20. Vanhems P, Voirin N, Roche S, et al. Risk of influenza-like illness in an acute health care setting during community influenza epidemics in 2004-2005, 2005-2006, and 2006-2007: A prospective study. Arch Intern Med 2011;171:151-7.

21. Voirin N, Barret B, Metzger MH, Vanhems P. Hospital-acquired influenza: A synthesis using the Outbreak Reports and Intervention Studies of Nosocomial Infection (ORION) statement. J Hosp Infect 2009;71:1-14.

22. King JC Jr, Stoddard JJ, Gaglani MJ, et al. Effectiveness of schoolbased influenza vaccination. N Engl J Med 2006;355:2523-32.

23. Loeb M, Russell ML, Moss L, et al. Effect of influenza vaccination of children on infection rates in Hutterite communities: A randomized trial. JAMA 2010;303:943-50.

24. van den Dool C, Bonten MJ, Hak E, Wallinga J. Modeling the effects of influenza vaccination of health care workers in hospital departments. Vaccine 2009;27:6261-7.

25. van den Dool C, Bonten MJ, Hak E, Heijne JC, Wallinga J. The effects of influenza vaccination of health care workers in nursing homes: Insights from a mathematical model. PLoS Med 2008;28;5:e200.

26. Report from the Medical Officer of Health on Influenza Immunization Rates of Healthcare Workers in Toronto Healthcare Facilities, May, 2011. <www.toronto.ca/legdocs/mmis/2011/hl/bgrd/ backgroundfile-38323.pdf> (Accessed January 21, 2012).

27. Lam PP, Chambers LW, MacDougall DM, McCarthy AE. Seasonal influenza vaccination campaigns for health care personnel: Systematic review. CMAJ 2010;182:E542-8.

28. Sartor C, Tissot-Dupont H, Zandotti C, Martin F, Roques P, Drancourt M. Use of a mobile cart influenza program for vaccination of hospital employees. Infect Control Hosp Epidemiol 2004;25:918-22.

29. Ajenjo MC, Woeltje KF, Babcock HM, Gemeinhart N, Jones M, Fraser VJ. Influenza vaccination among healthcare workers:
Ten-year experience of a large healthcare organization. Infect Control Hosp Epidemiol 2010;31:233-40.

30. Bertin M, Scarpelli M, Proctor AW, et al. Novel use of the intranet to document health care personnel participation in a mandatory influenza vaccination reporting program. Am J Infect Control 2007;35:33-7.

31. Cadena J, Prigmore T, Bowling J, et al. Improving influenza vaccination of healthcare workers by means of quality improvement tools. Infect Control Hosp Epidemiol 2011;32:616-8.

32. Babcock HM, Gemeinhart N, Jones M, Dunagan WC, Woeltje KF. Mandatory influenza vaccination of health care workers: Translating policy to practice. Clin Infect Dis 2010;50:459-64.

33. Miller BL, Ahmed F, Lindley MC, Wortley PM. Increases in vaccination coverage of healthcare personnel following institutional requirements for influenza vaccination: A national survey of U.S. hospitals. Vaccine 2011;29:9398-403.

34. Talbot TR, Dellit TH, Hebden J, Sama D, Cuny J. Factors associated with increased healthcare worker influenza vaccination rates: Results from a national survey of university hospitals and medical centers. Infect Control Hosp Epidemiol 2010;31:456-62.

35. Hirsch P, Hodgson M, Davey V. Seasonal influenza vaccination of healthcare employees: Results of a 4-year campaign. Infect Control Hosp Epidemiol 2011;32:444-8.

36. Centers for Disease Control and Prevention: State immunization laws for healthcare workers and patients. <www2a.cdc.gov/nip/ statevaccapp/statevaccsapp/default.asp $>$ (Accessed January 21, 2012).

37. Esolen LM, Kilheeney KL, Merkle RE, Bothe A. An alternate approach to improving healthcare worker influenza vaccination rates. Infect Control Hosp Epidemiol 2011;32:703-5.

38. Feemster KA, Prasad P, Smith MJ, et al. Employee designation and health care worker support of an influenza vaccine mandate at a large pediatric tertiary care hospital. Vaccine 2011;29:1762-9.

39. Rea E, Upshur R. Semmelweis revisited: The ethics of infection prevention among health care workers. CMAJ 2001;164:1447-8.

40. Rodal R, Ries NM, Wilson K. Influenza vaccination for health care workers: Towards a workable and effective standard. Health Law J 2009; 17:297-337.

41. Wynia MK. Mandating vaccination: What counts as a "mandate" in public health and when should they be used? Am J Bioeth 2007;7:2-6. 


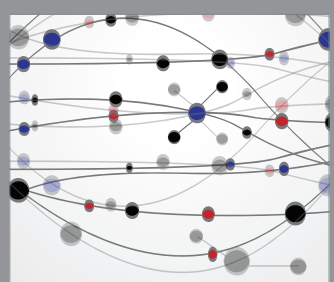

The Scientific World Journal
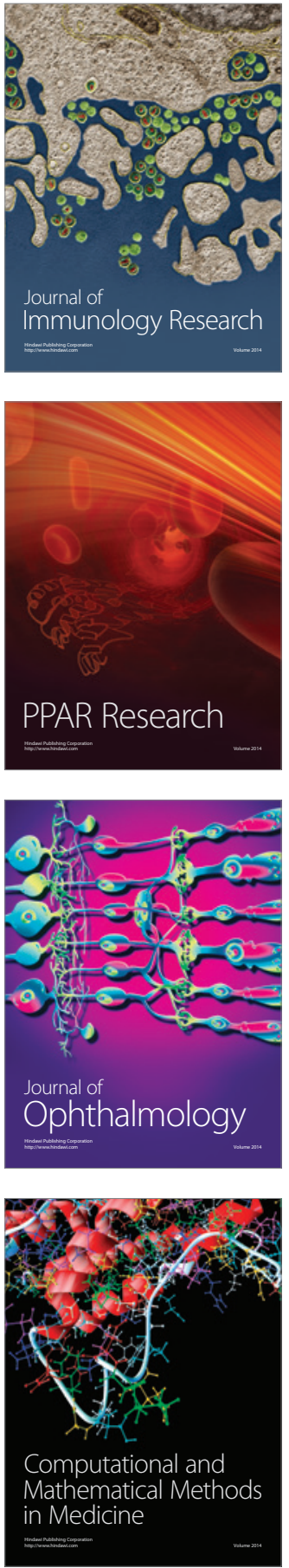

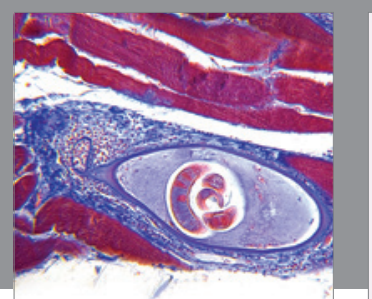

Gastroenterology Research and Practice

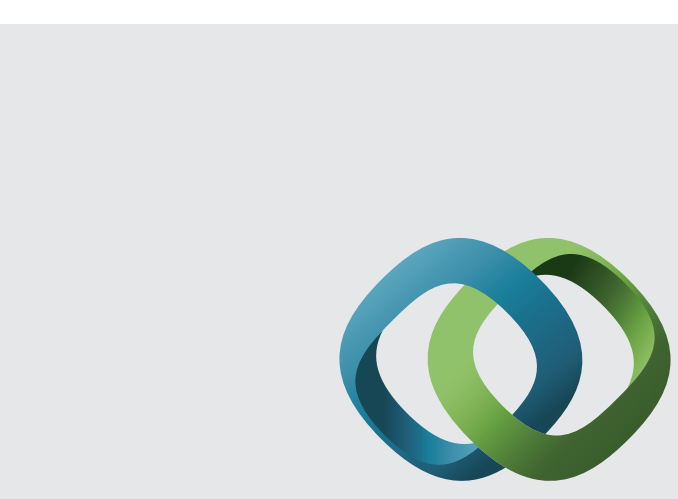

\section{Hindawi}

Submit your manuscripts at

http://www.hindawi.com
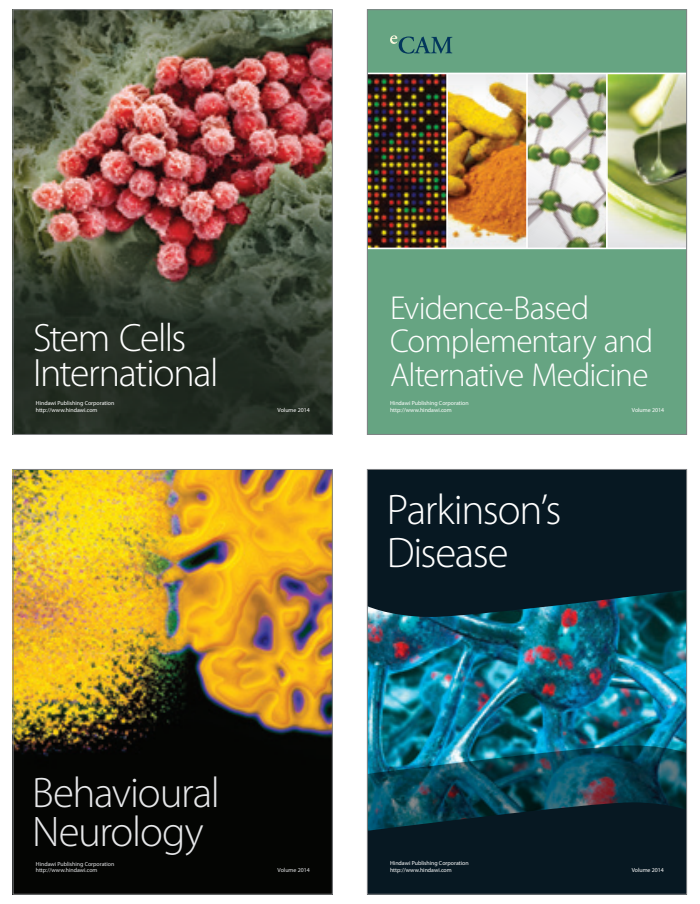
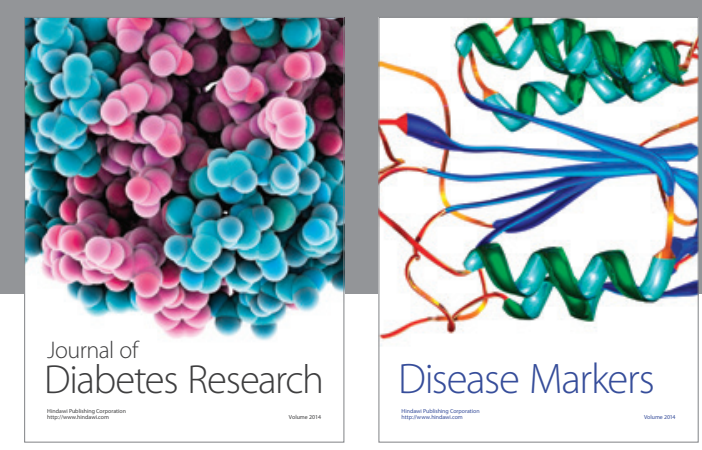

Disease Markers
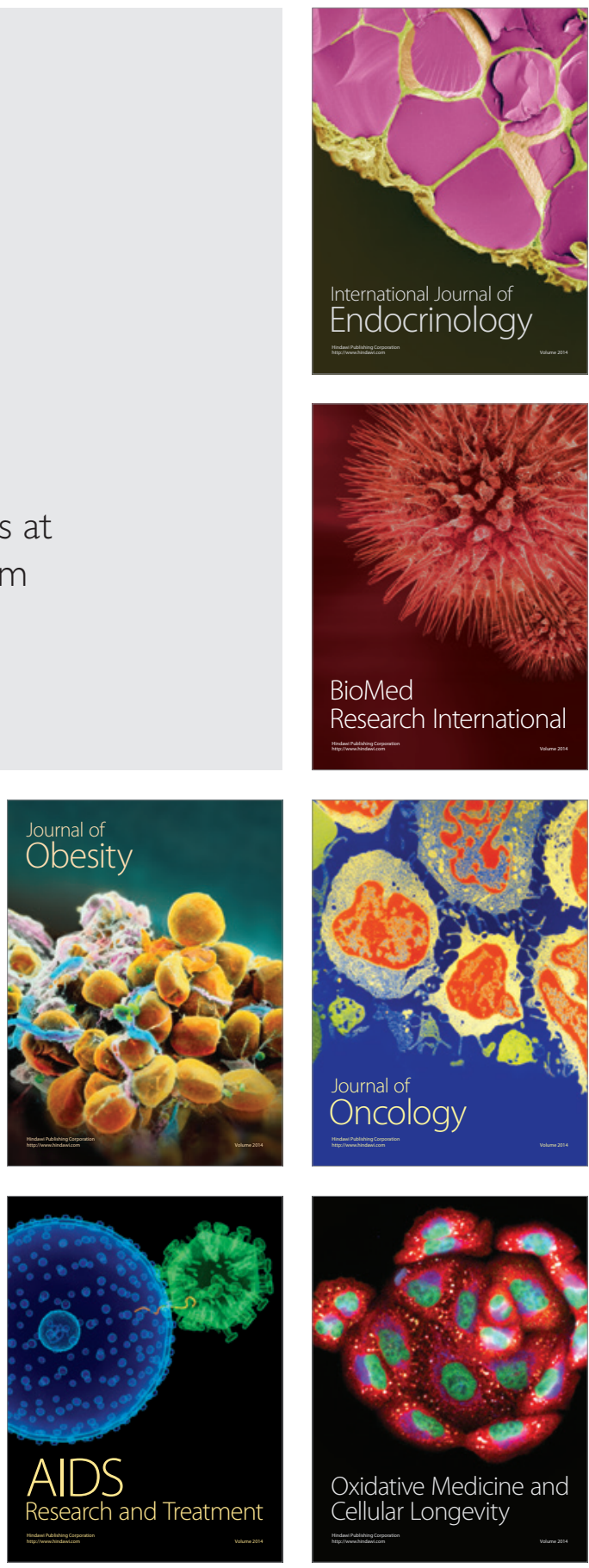